\title{
İktisadi Küreselleşmenin ve Finansal Kalkınmanın Türkiye'deki Karbondioksit Emisyonuna Etkisi: Çok Boyutlu İndeksler Yeni Bulgular Sunuyor Mu?*
}

\author{
The Impacts of Economic Globalization and Financial Development on \\ Turkey's Carbon Dioxide Emissions: Do Multi-Dimensional Indices Provide \\ Fresh Evidence?
}

Alper KARASOY ${ }^{1}$ (D)

\begin{abstract}
Öz
Bu araştırmada, iktisadi küreselleşmenin ve finansal kalkınmanın Türkiye'deki çevresel etkileri çok boyutlu indeksler üzerinden incelenmiştir. Üç modelin tahmin edildiği bu araştırmada, 1980-2016 dönemi temel alınmış ve yöntem olarak genişletilmiş dağıtılmış gecikmeli otoregresif (genişletilmiş $A R D L$ ) sınır testi yaklaşımı kullanılmıştır. Araştırmanın bulgularına göre, uzun dönemde, iktisadi ve finansal küreselleşmenin Türkiye'deki karbondioksit emisyonunu etkilemediği fakat ticari küreselleşmenin karbondioksit emisyonunu azalttığı bulunmuştur. İlaveten, kısa dönemde, iktisadi küreselleşme (ticari ve finansal küreselleşme boyutları da dahil olmak üzere) karbondioksit emisyonunu etkilememektedir. Ayrıca finansal kalkınmanın (uzun dönemde veya kısa dönemde) karbondioksit emisyonunu arttırdığı da tespit edilmiştir. Bu sonuçlar, araştırmada kullanılmış kontrol değişkenlerine (gelir, gelirin karesi, enerji tüketimi, sanayileşme ve kentleşme) ait bulgularla birlikte değerlendirilerek çeşitli politika önerileri ileri sürülmüştür.
\end{abstract}

Anahtar kelimeler: Karbondioksit emisyonu, iktisadi küreselleşme indeksi, finansal kalkınma indeksi, Türkiye, genişletilmiş ARDL yaklaşımı

Jel Sınıflaması: C51, F64, Q56

\section{ABSTRACT}

This research investigates the environmental impacts of economic globalization and financial development in Turkey by considering multidimensional indices. Three models are estimated in this research for the 1980-2016 period by employing the augmented autoregressive distributed lag (augmented $A R D L$ ) bounds testing procedure. According to the findings,

\section{DOI: 10.26650/JEPR861293}

*Bu araştırma, Afyon Kocatepe Üniversitesi'nin Sosyal Bilimler Enstitüsü Iktisat Anabilim Dalı'nda ve Prof. Dr. Selçuk AKÇAY danışmanlığında yazar tarafından hazırlanmış olan "Globalleşme, Sanayileşme ve Şehirleşmenin Çevresel Bozulma Üzerindeki Etkisinin Incelenmesi: Türkiye İ̧in Ekonometrik Bir Uygulama" başlıklı doktora tezinden (Tez No: 657364) elde edilmiştir.

'Afyon Kocatepe Üniversitesi, İktisadi ve İdari Bilimler Fakültesi, İktisat Bölümü, Afyonkarahisar, Türkiye

ORCID: A.K. 0000-0001-9447-3375

\section{Sorumlu yazar/Corresponding author:} Alper KARASOY,

Afyon Kocatepe Üniversitesi, İktisadi ve İdari Bilimler Fakültesi, İktisat Bölümü, Afyonkarahisar, Türkiye

E-posta/E-mail: akarasoy@aku.edu.tr

Başvuru/Submitted: 14.01.2021

Kabul/Accepted: 06.04.2021

Atıf/Citation: Karasoy, A. (2021). iktisadi küreselleșmenin ve finansal kalkınmanın Türkiye'deki karbondioksit emisyonuna etkisi: Çok boyutlu indeksler yeni bulgular sunuyor mu? Iktisat Politikası Araştırmaları Dergisi JournalofEconomicPolicyResearches, 8(2), 75-100. https://doi.org/10.26650/JEPR861293 
in the long run $(L R)$, economic and financial globalization do not affect Turkey's carbon dioxide emissions, whereas trade globalization decreases them. Additionally, in the short-run (SR), economic, trade, and financial globalization do not impact Turkey's carbon emissions. Moreover, financial development intensifies carbon dioxide emissions either in the LR or in the SR. These results, coupled with the evidence retrieved from control variables (income, income squared, energy consumption, industrialization, and urbanization), are utilized to put forward various policy suggestions.

Keywords: Carbon dioxide emissions, economic globalization index, financial development index, Turkey, augmented ARDL approach

Jel Classification: C51, F64, Q56

\section{EXTENDED ABSTRACT}

In the recent literature, many studies have been conducted to examine the determinants of carbon emissions in Turkey. However, many failed to completely capture the effects of the economic globalization and financial development processes experienced in Turkey since the 1980s. They failed because many of them investigated the impacts of these variables on carbon emissions via one-dimensional and limited indicators. For instance, to examine the impact of economic globalization/liberalization, only two proxies, namely trade openness (imports and/or exports as a share of output) and/or foreign direct investments (FDIs), are considered in the existing literature on Turkey (e.g., Cetin \& Ecevit, 2017; Karasoy, 2019; Özdemir \& Koç, 2020; Öztürk \& Saygın, 2020; Z. Öztürk \& Öz, 2016). Similarly, to elucidate the financial development's impact on Turkey's carbon emissions, domestic credit (provided by the financial sector or to the private sector) is the most frequently employed variable (see, e.g., Dar \& Asif, 2018; Gokmenoglu, Taspinar \& Rahman, 2020; Ozatac, Gokmenoglu \& Taspinar, 2017; Ozturk \& Acaravci, 2013).

Although these variables (trade volume, FDIs, and domestic credits) are almost always adopted as proxies for economic liberalization and financial development in the empirical literature for environmental economics, these variables are one-dimensional, and it might be misleading to proxy multi-dimensional concepts such as economic globalization and financial development with one-dimensional variables. To overcome this issue, this research aims to make the following contributions to the extant literature on Turkey:

First, this study proxies economic liberalization/globalization with an economic globalization index constructed by Gygli, Healg, Potrafke and Sturm (2019). This index, which consists of two sub-indices (trade and financial globalization), encompasses not only trade volume and FDIs but also other indicators such as trade partner diversity, portfolio investments, and international reserves/debt that can help capture the economic globalization process better. Besides the economic globalization index, its sub-indices (trade and financial globalization) are also included in different models to decompose economic globalization's effect on carbon emissions. 
Second, this research also employs the financial development index calculated by Svirydzenka (2016). Similar to the economic globalization index, this financial development index is constructed by accounting for different dimensions (financial markets and institutions) and aspects (depth, access, and efficiency) of financial development. Employing such a multi-dimensional index to capture the financial development's effect on carbon emissions is more appropriate, as financial development is defined as a multifaceted process (Svirydzenka, 2016, p. 4).

By including these indices in its models, this research aims to capture how these processes (economic globalization and financial development) impacted Turkey's carbon emissions and provide multi-dimensional policies. An additional contribution of this research is in its method. In this study, the augmented autoregressive distributed lag (augmented $A R D L$ ) bounds testing approach, which is developed by McNown, Sam, and Goh (2018) and Sam, McNown, and Goh (2019), is utilized. The main advantage of this method is that, unlike the typical ARDL approach of Pesaran, Shim, and Smith (2001), it allows the dependent variable (carbon dioxide emissions) in the models to be a nonintegrated process (i.e., $I(0)$ ). This property is rather practicable because unit-root tests usually provide conflicting results.

Moreover, in line with the literature, besides economic globalization and financial development indices, this research includes additional control variables (income, income squared, energy consumption, industrialization, and urbanization) in its models to minimize the omitted variable bias. The findings of this research show that while economic and financial globalization do not significantly affect carbon emissions in Turkey, trade globalization negatively affects them in the long run. Furthermore, financial development intensifies Turkey's carbon dioxide emissions. Additional findings also imply that energy consumption, industrialization, and urbanization amplify carbon dioxide emissions in Turkey. Lastly, income does not have an inverted-U shape impact on carbon emissions in the majority of the estimated models, indicating that the environmental Kuznets curve hypothesis is not valid for the sample period. In the light of these findings, some policy implications are stated. 


\section{GİRIŞ}

Küresel ısınma ve beraberinde getirdiği iklim değişikliği gibi çeşitli çevresel sorunlar dünyamızı tehdit etmeye devam etmektedir. Her ne kadar Paris İklim Anlaşması gibi çeşitli uluslararası anlaşmalarla küresel ısınmayı (ve karbondioksit emisyonunu) kontrol altına almaya yönelik bazı küresel adımlar atılmış olsa da bu tarz anlaşmaların henüz global düzeyde anlamlı bir etki yaratmadığı öne sürülebilir. Küresel ısınmanın ve sera gazı emisyonunun sıklıkla kullanılan göstergelerinden olan karbondioksit emisyonu artmaya devam etmektedir. Örneğin, dünyadaki karbondioksit emisyonu 1980 yılında yaklaşık 18.389 milyon ton iken 2016 yılında, neredeyse \%79'luk bir artışla, 32.914 milyon ton seviyelerine yükselmiştir (BP Statistical Review of World Energy, 2019).

Türkiye'nin küresel ısınmaya ya da bir başka ifadeyle karbondioksit emisyonuna katkısı -her ne kadar sınırlı da olsa- artmaktadır. Örneğin, Türkiye'nin dünyadaki toplam karbondioksit emisyonundaki payı, 1980'lerin başında \%0,5'in altındayken 2016 itibariyle \%1'in üzerine çıkmıştır (BP Statistical Review of World Energy, 2019). Bu oran görece az bulunabilir fakat Türkiye'nin ekonomik ve karbondioksit emisyonu büyüme oranları, diğer bölgelerin ve dünyanın ortalama büyüme oranlarıyla karşılaştırıldığında durumun ciddiyeti daha iyi anlaşılabilir. Bu çerçevede Tablo 1'de sunulmuş olan, Türkiye, AB, OECD ve dünyanın ekonomik büyüme ve karbon salımı büyüme oranları incelenebilir. 
Tablo 1: Türkiye, AB, OECD ve Dünyada Ekonomik Büyüme ve Karbon Salımının Büyüme Oranları

\begin{tabular}{lcccc}
\hline \multicolumn{5}{c}{ A) Gelirin Büyüme Oranları } \\
\hline Yıllar & Türkiye & $\mathbf{A B}$ & OECD & Dünya \\
\hline $1980-84$ & 1,228 & 1,123 & $\mathbf{1 , 3 7 4}$ & 0,458 \\
$1985-89$ & 2,666 & 2,807 & $\mathbf{2 , 9 2 8}$ & 2,025 \\
$1990-94$ & 1,899 & 1,379 & 1,255 & 0,509 \\
$1995-99$ & $\mathbf{2 , 7 1 7}$ & 2,476 & 2,251 & 1,726 \\
$2000-04$ & $\mathbf{2 , 9 5 7}$ & 1,903 & 1,697 & 1,873 \\
$2005-09$ & $\mathbf{2 , 1 7 6}$ & 0,661 & 0,354 & 1,305 \\
$2010-14$ & $\mathbf{5 , 9 1 1}$ & 0,843 & 1,301 & 1,887 \\
2015 & $\mathbf{4 , 3 3 3}$ & 2,134 & 1,754 & 1,691 \\
2016 & 1,513 & 1,834 & 1,059 & 1,413 \\
$1980-2016$ & & & 1,406 \\
Dönemi Ort. & $\mathbf{2 , 8 0 1}$ & 1,620 & 1,584 & \\
Büyüme & & & & \\
\hline
\end{tabular}

\begin{tabular}{|c|c|c|c|c|}
\hline \multicolumn{5}{|c|}{ B) Karbondioksit $\left(\mathrm{CO}_{2}\right)$ Emisyonunun Büyüme Oranları } \\
\hline Yillar & Türkiye & $\mathrm{AB}$ & OECD & Dünya \\
\hline $1980-84$ & 5,044 & $-2,069$ & $-1,319$ & 0,290 \\
\hline $1985-89$ & 7,234 & 1,044 & 1,740 & 2,389 \\
\hline $1990-94$ & 2,630 & $-1,847$ & 0,377 & 0,457 \\
\hline $1995-99$ & 5,068 & 0,288 & 1,369 & 1,320 \\
\hline 2000-04 & 3,187 & 0,900 & 1,087 & 3,201 \\
\hline 2005-09 & 5,000 & $-1,971$ & $-1,368$ & 1,930 \\
\hline $2010-14$ & 4,228 & $-2,072$ & 0,043 & 2,032 \\
\hline 2015 & 2,542 & 1,266 & $-0,984$ & $-0,123$ \\
\hline 2016 & 5,753 & 0,358 & $-0,602$ & 0,333 \\
\hline 1980-2016 & & & & \\
\hline $\begin{array}{l}\text { Dönemi Ort. } \\
\text { Büyüme }\end{array}$ & 4,602 & $-0,730$ & 0,218 & 1,576 \\
\hline
\end{tabular}

Not: Yazar tarafından, Dünya Bankası'nın “Dünya Kalkınma Göstergeleri” (World Development Indicators) (The World Bank, 2020) ve BP'nin (BP Statistical Review of World Energy, 2019) veri tabanlarından elde edilen seriler kullanılarak hesaplanmıştır. Büyüme oranları yüzdedir (\%). Dönem ve yıllara göre baskın değerler kalın fontla gösterilmiştir. Gelir, gayrisafi yurtiçi hâsıla (GSYH) ile gösterilmektedir. OECD: Ekonomik Kalkınma ve İş Birliği Örgütü, AB: Avrupa Birliği.

Tablo 1'in A panelindeki verilere göre Türkiye'nin 1980-2016 dönemindeki ekonomik büyüme performansı hem AB hem OECD hem de dünya ortalamalarının, genel olarak, üzerinde kalmıştır. Bu ekonomik büyüme performansında, Türkiye'de özellikle 1980 sonrası gerçekleşen iktisadi serbestleşme ve beraberinde gelen sanayileşme, kentleşme ve finansal kalkınma süreçlerinin de etkili olduğu ileri sürülebilir. Fakat yine aynı tablonun B panelindeki veriler incelendiğinde, bu büyüme performansıyla beraber karbondioksit emisyonunda da olağanüstü artışlar yaşandığı görülmektedir. Özellikle 1980-2016 döneminde karbondioksit emisyonunun ortalama büyüme oranı $\% 4,6$ 'dır ve bu oran, dünya ortalamasının $(\% 1,58)$ neredeyse üç katı kadardır. Ek olarak bu oranlar, Türkiye'deki enerji verimliliğinin düşük olduğuna ve enerji kompozisyonun baskın olarak fosil yakıtlarından 
oluştuğuna da işaret etmektedir. Örneğin, AB ve OECD ülkelerinin ortalama ekonomik büyüme oranları pozitifken $(\% 1,62$ ve $\% 1,58)$ karbondioksit emisyonunda yaşanan büyüme oranları AB için negatif (-\%0,73) ve OECD içinse sadece \%0,22’dir. Fakat Türkiye'deki ekonomik büyüme oranı $(\% 2,8)$, karbon emisyonu büyüme oranının $(\% 4,6)$ çok altında kalmıştır.

Türkiye'de enerji tüketimindeki ve karbondioksit emisyonundaki artış eğilimlerinin devam edeceği ve Türkiye'nin iklim değişikliğiyle mücadele kapsamında (karbondioksit emisyonunu sınırlamaya yönelik) ileri sürmüş olduğu Ulusal Niyet Beyanı'nın da yetersiz olduğu konusunda çeşitli çalışmalar vardır (bkz. CAT, 2020; Day, Gonzales, and Röschel, 2016; Difiglio, Güray, and Merdan, 2020). Bütün bu problemler ele alındığında, Türkiye'de özellikle 1980 sonrası yaşanan iktisadi globalleşme sürecinin ülkedeki karbondioksit emisyonunu nasıl etkilediğinin anlaşılmasının, politika koyucularına daha farklı ve kapsamlı bakış açıları sunacağı öne sürülebilir.

Bu çerçevede, bu görgül araştırmanın ana amacı da 1980 sonrası Türkiye'de yaşanan iktisadi globalleşme sürecinin ve bu sürecin getirmiş olduğu finansal kalkınmanın ülkedeki karbon emisyonunu nasıl etkilediğini incelemektir. Bu çalışmanın var olan literatüre katkısı şu maddelerle özetlenebilir:

(1) Bu çalışmanın literatür incelemesi bölümünde gösterildiği üzere, Türkiye'deki karbon emisyonunun belirleyicilerini inceleyen birçok çalışma vardır. Fakat bu çalışmaların neredeyse tamamı ülkede yaşanan iktisadi küreselleşme ve finansal kalkınma süreçlerini tek boyutlu değişkenler üzerinden ele almaktadır. Bu çalışmaların aksine bu araştırmada iktisadi globalleşme süreci, çeşitli ticari ve finansal serbestleşme göstergeleri kullanılarak oluşturulmuş olan bir indeks ve bu indeksin alt-indeksleri (ticari ve finansal globalleşme) üzerinden ele alınacaktır. Aynı şekilde, finansal kalkınmanın etkisi de birçok finansal değişkenin kullanılmasıyla oluşturulmuş bir indeks üzerinden değerlendirilecektir. Böylece Türkiye'de yaşanan iktisadi serbestleşme ve finansal kalkınma süreçlerinin karbon emisyonuna etkisi daha kapsamlı bir şekilde irdelenmiş/ayrıştırılmış olacak ve bu kapsamda çok boyutlu politikalar da sunulacaktır.

(2) Var olan literatürle uyumlu bir şekilde bu çalışmada, sadece iktisadi küreselleşme ve finansal kalkınma değil aynı zamanda çeşitli kontrol değişkenlerinin (gelir, gelirin karesi, enerji tüketimi, kentleşme ve sanayileşme) de karbon emisyonunu nasıl etkilediği tahmin edilecektir. Böylece hem çalışmanın kapsamının genişletilmesi hem de dışlanmış değişkenler sorununun da bertaraf edilmesi planlanmaktadır.

(3) Son olarak, bu çalışmada genişletilmiş dağıtılmış gecikmeli (augmented $A R D L$ ) sınır testi yaklaşımı kullanılacaktır. Bu yaklaşımın Pesaran ve ark.'nın (PSS) (2001) klasik 
ARDL yaklaşımından farkı, bağımsız değişkenlerin yanında bağımlı değişkenin de düzeyde durağan $(I(0))$ olmasına izin vermesidir.

Bu araştırmanın yapısı şu şekildedir: Birinci bölümde, iktisadi globalleşme ve finansal kalkınmanın çevre kirliliğini (karbondioksit emisyonunu) hangi kanallar üzerinden etkileyebileceği kavramsal olarak açıklanmıştır. Devamındaki bölümde, kısa bir literatür incelemesine yer verilmiştir. Üçüncü bölümde, bu çalışmada kullanılan iktisadi globalleşme ve finansal kalkınma indekslerinin yapıları özetlenmiştir. Dördüncü bölümdeyse değişkenler, tahmin edilecek modeller ve bu tahmin sürecinde kullanılan yöntem izah edilmiştir. Beşinci kısımda, elde edilen tahmin sonuçları sunulmuştur. Son kısımda da bu sonuçlar üzerinden çeşitli politika önerileri ileri sürülmüştür.

\section{1. İKTİSADİ KÜRESELLEŞME VE FINANSAL KALKINMANIN KARBONDİKSITT EMISYONUNA ETKISİ}

\section{1. İktisadi Küreselleşmenin Çevresel Etkileri}

İktisadi globalleşme, sınır ötesi mal ve hizmet ticaretinin yanında sermaye hareketlerinin ve teknolojinin de hızla yayılması ve böylece dünya ekonomilerinin birbirlerine bağımlı hale gelmesiyle oluşan bir süreç olarak tanımlanabilir (Shangquan, 2000, s.1).

İktisadi küreselleşmenin çevresel etkileri de genellikle dış ticaret ve doğrudan yabancı yatırımların (DYY'lerin) olası etkileri üzerinden ele alınmıştır. Birdsall \& Wheeler (1993, s. 139) çalışmalarında, dış ticaretin (ve DYY'lerin) çevresel sonuçlarını üç etki üzerinden değerlendirmişlerdir: Kalkınma (development), kompozisyon (composition) ve süreç (process) etkileri. Kalkınma etkisi, iktisadi serbestleşmeyle birlikte ortaya çıkan sanayileşme ve kentleşme süreçlerinin getirdiği ekonomik büyüme etkisini kapsamaktadır. Kompozisyon ve süreç etkileri de ilgili ülkenin üretim kompozisyonunda ve sürecinde meydana gelecek değişimin çevresel etkilerini yansıtmaktadır. İktisadi serbestleşmenin çevre üzerindeki kompozisyon etkisi, dışa açılan ülkenin üretiminde yoğunlaştığı ürünün içeriğine göre değişebilir: Eğer ilgili ülke emek yoğun ürünlerin üretiminde uzmanlaşırsa dış ticaretin karbon emisyonuna etkisi negatiftir fakat uzmanlaşılan ürünler, sermaye yoğun ise diş ticaretin karbon emisyonunu arttırması beklenebilir (Birdsall \& Wheeler, 1993, s. 139-140; Saini \& Sighania, 2019, s.123-124).

Son etki olan süreç etkisine göre, ticari serbestlikle birlikte gelişmiş ülkelerden gelişmekte olan ülkelere gelecek olan yatırımlar rekabeti arttıracak ve çevre dostu üretim teknikleri sayesinde de bu yatırımların çevresel zararları sınırlı olacaktır. Bu durumda hem rekabet artışı hem de çevre dostu üretim tekniklerinin standart haline gelmesi sebebiyle var olan yatırımlar ya piyasadan çekilecekler ya bu yeni üretim tekniklerini adapte edecekler ya 
da kendi temiz üretim teknolojilerini geliştirerek uygulayacaklarıdır. Bunun sonucunda da çevre üzerindeki baskı azalacaktır (Birdsall \& Wheeler, 1993, s.139-140).

K1sacası, bu etkiler değerlendirildiğinde, iktisadi küreselleşmenin/serbestleşmenin karbon emisyonuna etkisinin belirsiz olduğu ileri sürülebilir.

\subsection{Finansal Kalkınmanın Karbondioksit Emisyonuna Etkisi}

Mishkin'e (2009, s. 164) göre (iktisadi) küreselleşme, gelişmekte olan ülkelerde finansal kalkınmayı (FK) ve iktisadi büyümeyi teşvik edecek kurumsal reformların hayata geçirilmesinde etkili olan ana faktördür. Başka bir ifadeyle iktisadi küreselleşme, yerli piyasaları yabancı (finansal) yatırımcılara açacağı için finansal sistemlerin fonksiyonlarının genişletilip, geliştirilmesini mümkün kılacaktır (Mishkin, 2009, s. 166). Bu yüzden, iktisadi küreselleşmenin yanında FK'nın da çevresel etkilerinin değerlendirilmesi daha kapsamlı bulgular elde etmemize olanak tanıyabilir.

Literatürde, FK'nin çevresel etkileri konusunda çelişen görüşler vardır. Örneğin, Tamazian, Chousa, and Vadlamannati (2009) çalışmasına göre finansal serbestleşme ve kalkınma ülkeye daha fazla DYY gelmesini teşvik edecek ve bu da o ülkedeki Ar-Ge yatırımlarını da tetikleyecektir. Bununla birlikte FK, kalkınmakta olan ülkelerdeki yatırımlara, erişilebilir ve düşük maliyetli kredi ve teşvikler de sağlayarak yeni ve çevre dostu üretim tekniklerinin adapte edilmesine de öncülük edebilir (Tamazian ve ark, 2009, s. 247).

Öte yandan Yuxiang \& Chen (2011) çalışmasına göre, FK'nın çevresel olumsuz etkileri olabilir. Bu çalışmaya göre FK, yatırımcıların var olan yatırımlarını arttırmasını veya yeni yatırımcıların piyasalara girmesini sağlayabilir. Bu yatırımcıların, ölçek ekonomilerinden faydalanamadığı da varsayılırsa yatırımlarda yaşanacak olan bu artış enerji tüketimini ve dolayısıyla karbondioksit emisyonunu da arttıracaktır. Bunun yanında, her ne kadar FK'nın getireceği teknoloji etkisi daha etkin üretim tekniklerinin adapte edilmesini sağlasa da bu etkinlik beraberinde daha fazla üretimi de getirerek, doğal kaynaklara ve enerjiye olan talebi arttırabilir. Bu durum da karbon emisyonunu arttırabilir (Yuxiang \& Chen, 2011, s. 96-97). $\mathrm{Bu}$ etkilerin yanı sıra FK, tüketicilerin de kredilere ulaşmasını kolaylaştıracağı için tüketicilerin enerji tüketimi yoğun olan dayanıklı tüketim mallarını (buzdolabı, otomobil, çamaşır ve/veya bulaşık makinesi vs.) satın almalarını sağlayacaktır. Böylece enerji tüketimiyle beraber karbondioksit salımı da artacaktır (Sadorsky, 2010, s. 2529).

Özetle, bu görüşler çerçevesinde, FK'nın çevresel bozulmaya etkisinin pozitif, negatif ya da anlamsız olabileceği öne sürülebilir. 


\section{2. İKTISSADİ KÜRESELLEŞME VE FINANSAL KALKINMANIN ÇEVRESEL ETKİLERİ: LITERATÜR ÖZETİ}

İktisadi küreselleşme ve FK'yı modellerinde değerlendirmiş ve Türkiye üzerine yapılmış güncel ampirik çalışmaların özeti Tablo 2'de sunulmuştur. Tablo 2 incelendiğinde iki bulgu öne çıkmaktadır: (i) İktisadi globalleşme, baskın olarak iki değişken üzerinden ele alınmıştır ve bunlar dış ticaret hacmi ile doğrudan yabancı yatırımlardır. Sonuçlara göre, bu değişkenlerin Türkiye'deki karbon emisyonuna etkileri pozitif ya da negatif olabilmektedir. (ii) FK'nın çevresel etkileri de genel olarak (özel sektöre sağlanan veya finans sektörünün sağladığ1) yurt içi krediler ve para arz1 (M2 ya da M3) değişkenleri üzerinden değerlendirilmiştir. Buradaki tek istisna Katircioğlu ve Taşpinar (2017) çalışmasıdır. Bu çalışmada, beş finansal değişken üzerinden elde edilmiş bir finansal kalkınma indeksi kullanılmıştır. Ek olarak çalışmaların sonuçlarına göre FK'nın Türkiye'deki karbon emisyonuna etkisi belirsizdir.

Kısacası, Türkiye üzerine yapılmış olan çalışmalarda iktisadi küreselleşme ve finansal kalkınma değişkenleri genellikle tek boyutlu ve sınırlı göstergeler üzerinden ele alınmıştır. Bu çalışmada -sonraki bölümde de açıklandığı üzere- bu değişkenler, birçok farklı gösterge üzerinden hesaplanmış olan indeksler aracılığıyla değerlendirilmiştir. Böylece bu değişkenlerin çevresel etkilerinin daha kapsamlı bir şekilde gözlenebilmesi amaçlanmıştır. 
Tablo 2: Literatür Özeti: Türkiye'yi Konu Alan Çalışmalarda Kullanılmış İktisadi Küreselleşme ve Finansal Kalkınma Değişkenleri

\begin{tabular}{|c|c|c|c|c|c|}
\hline Çalışma & Dönem & $\begin{array}{c}\text { İktisadi } \\
\text { Serbestleşme } \\
\text { (Küreselleşme) } \\
\text { Değişkeni }\end{array}$ & $\begin{array}{c}\text { İktisadi } \\
\text { Serbestleşmenin } \\
\text { KE'ye Etkisi }\end{array}$ & $\begin{array}{c}\text { Finansal } \\
\text { Kalkınma (FK) } \\
\text { Değişkeni }\end{array}$ & $\begin{array}{c}\text { FK'nın } \\
\text { KE'ye etkisi }\end{array}$ \\
\hline $\begin{array}{l}\text { Özdemir \& Koç } \\
(2020)\end{array}$ & $1960-2017$ & Diş Ticaret & Pozitif & - & - \\
\hline $\begin{array}{l}\text { Öztürk \& Saygın } \\
(2020)\end{array}$ & $1974-2016$ & $\begin{array}{l}\text { DYY ve Diş } \\
\text { Ticaret }\end{array}$ & Pozitif & - & - \\
\hline $\begin{array}{l}\text { Gokmenoglu vd. } \\
(2020)\end{array}$ & $1960-2014$ & - & - & $\begin{array}{c}\text { Finans } \\
\text { sektörünün } \\
\text { sağladığı yurt içi } \\
\text { krediler }\end{array}$ & Negatif \\
\hline $\begin{array}{l}\text { Mert \& Caglar } \\
(2020)\end{array}$ & $1974-2018$ & DYY & Negatif & - & - \\
\hline Karasoy (2019) & $1965-2015$ & Dış Ticaret & Pozitif & $\begin{array}{l}\text { Likit } \\
\text { yükümlülükler } \\
\text { (M3) }\end{array}$ & Pozitif \\
\hline $\begin{array}{l}\text { Karasoy \& Akçay } \\
\text { (2019) }\end{array}$ & $1965-2016$ & Dış Ticaret & Pozitif & - & - \\
\hline $\begin{array}{l}\text { Koçak \& } \\
\text { Şarkgüneşi (2018) }\end{array}$ & $1974-2013$ & DYY & Pozitif & - & - \\
\hline Pata (2018) & $1974-2013$ & - & - & $\begin{array}{c}\text { Özel sektöre } \\
\text { sağlanan yurt içi } \\
\text { krediler }\end{array}$ & Pozitif \\
\hline Dar \& Asif (2018) & $1960-2013$ & - & - & $\begin{array}{c}\text { Özel sektöre } \\
\text { sağlanan yurt içi } \\
\text { krediler }\end{array}$ & Negatif \\
\hline $\begin{array}{l}\text { Akçay \& Karasoy } \\
(2018)\end{array}$ & $1974-2012$ & DYY & Negatif & $\begin{array}{c}\text { Para arzının } \\
\text { (M2) GSYH'ye } \\
\text { oranı }\end{array}$ & Negatif \\
\hline $\begin{array}{l}\text { Katircioglu \& } \\
\text { Celebi (2018) }\end{array}$ & $1960-2013$ & Diş Borçlar & Anlamsız & - & - \\
\hline $\begin{array}{l}\text { Kilıçarslan \& } \\
\text { Dumrul (2017) }\end{array}$ & $1960-2011$ & DYY & Pozitif & - & - \\
\hline $\begin{array}{l}\text { Katircioğlu \& } \\
\text { Taşpinar (2017) }\end{array}$ & $1960-2010$ & - & - & $\begin{array}{c}\text { Temel bileşenler } \\
\text { analiziyle } \\
\text { oluşturulmuş } \\
\text { finansal } \\
\text { kalkınma } \\
\text { indeksi }{ }^{\dagger}\end{array}$ & $\begin{array}{l}\text { Kisa dönemde } \\
\text { FK, gelirin } \\
\text { KE üzerindeki } \\
\text { arttırıcı etkisini } \\
\text { azaltırken } \\
\text { uzun dönemde } \\
\text { arttırmaktadır. }\end{array}$ \\
\hline Ozatac vd. (2017) & $1960-2013$ & D1ş Ticaret & Pozitif & $\begin{array}{c}\text { Özel sektöre } \\
\text { sağlanan yurtiçi } \\
\text { krediler }\end{array}$ & Anlamsiz \\
\hline $\begin{array}{l}\text { Cetin \& Ecevit } \\
(2017)\end{array}$ & $1960-2011$ & D1ş Ticaret & Pozitif & $\begin{array}{c}\text { Özel sektöre } \\
\text { sağlanan yurtiçi } \\
\text { krediler }\end{array}$ & Pozitif \\
\hline Öztürk \& Öz (2016) & $1974-2011$ & DYY & Negatif & - & - \\
\hline
\end{tabular}




\begin{tabular}{|c|c|c|c|c|c|}
\hline $\begin{array}{l}\text { Gokmenoglu \& } \\
\text { Taspinar (2016) }\end{array}$ & $1974-2010$ & DYY & Pozitif & - & - \\
\hline Seker vd. (2015) & $1974-2010$ & DYY & Pozitif & - & - \\
\hline $\begin{array}{l}\text { Destek \& Ozsoy } \\
\text { (2015) }\end{array}$ & $1970-2010$ & $\begin{array}{c}\text { İktisadi } \\
\text { Küreselleşme } \\
\text { İndeksi }\end{array}$ & Negatif & - & - \\
\hline $\begin{array}{l}\text { Ozturk \& Acaravci } \\
\text { (2013) }\end{array}$ & $1960-2007$ & Dış Ticaret & Pozitif & $\begin{array}{l}\text { Özel sektöre } \\
\text { sağlanan yurtiçi } \\
\text { krediler }\end{array}$ & Anlamsız \\
\hline
\end{tabular}

†: Bu indeksin oluşturulmasında kullanılan değiş̧kenler: (i) özel sektöre sağlanan ve (ii) bankacılık sektörü tarafindan sağlanan yurt içi krediler, (iii) Para arzı (M2), (iv) Ticari bankaların varlıklarının Merkez Bankası'nın ve ticari bankaların toplam varlıklarına oranı ve (v) Likit yükümlülüklerdir (M3). DYY: Doğrudan yabancı yatıımlar. Dış Ticaret: İthalat ve ihracat. KE: Karbondioksit emisyonu.

\section{3. İKTİSADİ KÜRESELLEŞME VE FİNANSAL KALKINMA İNDEKSLERİ}

\section{1. İktisadi Küreselleşme İndeksinin Yapısı}

Bu çalışmada kullanılacak olan iktisadi küreselleşme indeksi, Dreher (2006) ve Gygli ve ark. (2019) tarafından oluşturulmuş fiili (de facto) iktisadi küreselleşme indeksidir. Bu indeksin içeriği Şekil 1'de sunulmuştur.

\section{Şekil 1. İktisadi, Ticari ve Finansal Küreselleşme İndekslerinin Yapısı}

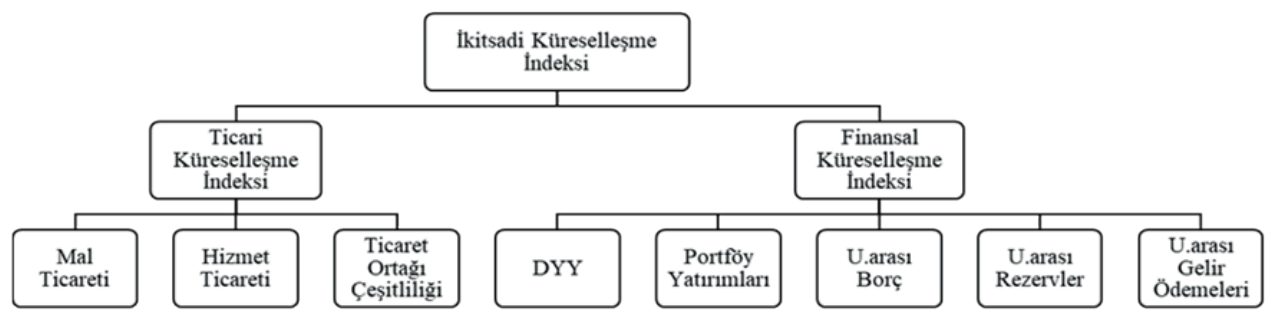

Not: Fiili indeksler kullanılmıştır. İndekslerin içerikleri https://ethz.ch/content/dam/ethz/special-interest/dual/kof-dam/documents/ Globalization/2019/KOFGI_2019_structure.pdf adresinden alınmış ve yazar tarafından Türkçeye tercüme edilmiştir (Erişim tarihi: 30.05.2020).

Şekil 1'de sunulan iktisadi küreselleşme indeksi, iki alt-indeksin (ticari ve finansal globalleşme indekslerinin) eşit ağırlıklarla $(0,5)$ toplanmasıyla elde edilmektedir ${ }^{1}$. Bu altindeksler de ilgili değişkenlerin temel bileşenler yöntemiyle bir araya getirilmesiyle elde edilmiştir. Ticari küreselleşme indeksi, mal ve hizmet ticareti (GSYH'ye oranı) ile ticaret ortağ1 çeşitliliği değiş̧kenlerinden elde edilmiştir. Finansal küreselleşme indeksi de DYY'lerin yanında portföy yatırımlarını, uluslararası borçları, rezervleri ve gelir ödemelerini içermektedir. Ek olarak kullanılan indeks (ve alt-indeksleri), 0 (düşük globalleşme) ile 100 (yüksek globalleşme) arasında değerler almaktadır. Önceki bölümde incelenmiş olan ampirik

\footnotetext{
${ }^{1}$ Ayrıntı için bkz. Gygli vd. (2019).
} 
çalışmalarla karşılaştırıldığında, bu indeksin daha kapsamlı ve nitelikli bir şekilde iktisadi küreselleşmeyi yansıttığı düşünülmektedir.

Bu çalışmada tahmin edilecek modellerde, Şekil 1'de gösterilen iktisadi küreselleşme indeksinin $[\operatorname{Model}(A)]$ yanında ticari ve finansal küreselleşme [Model $(B)$ ve $(C)]$ indeksleri de ayrı ayrı ele alınacaktır. Böylece iktisadi küreselleşmenin ticari ve finansal boyutları da ayrıştırılmış olacaktır.

\subsection{Finansal Kalkınma İndeksinin Yapısı}

Bu çalışmada kullanılmış olan finansal kalkınma indeksi, Svirydzenka (2016) tarafından oluşturulmuş bir indekstir. Bu indeksin içeriği Tablo 3 'te gösterilmiştir².

Tablo 3: Finansal Kalkınma İndeksinin Yapısı

\begin{tabular}{|c|c|c|}
\hline $\begin{array}{l}\text { Indeksin } \\
\text { Kategorisi }\end{array}$ & \multicolumn{2}{|c|}{ Değişkenler } \\
\hline \multicolumn{3}{|c|}{ Finansal Kurumlar } \\
\hline \multirow{4}{*}{ Derinlik } & Özel sektör kredileri & \multirow{4}{*}{ GSYH'ye oranı } \\
\hline & Emeklilik fonu varlıkları & \\
\hline & Yatırım fonu varlıkları & \\
\hline & Sigorta primleri (hayat ve hayat dışı) & \\
\hline \multirow{2}{*}{ Erişim } & Banka şubeleri (100.000 yetişkin başına) & \multirow{2}{*}{100.000 yetişkin başına } \\
\hline & Bankomat sayısı(100.000 yetişkin başına) & \\
\hline \multirow{6}{*}{ Etkinlik } & Net faiz marjı & - \\
\hline & Borç verme ve mevduat faiz oranı farkı & - \\
\hline & Faiz dış1 gelir & Toplam gelire oranı \\
\hline & Sabit maliyetler & Toplam varlıklara oranı \\
\hline & Aktif kârlılık & - \\
\hline & Öz sermaye kârlılığı & - \\
\hline \multicolumn{3}{|c|}{ Finansal Piyasalar } \\
\hline \multirow{5}{*}{ Derinlik } & Borsa büyüklüğü & \multirow{5}{*}{ GSYH'ye oranı } \\
\hline & İşlem görmüş hisse senetleri & \\
\hline & $\begin{array}{l}\text { Hükümete ait uluslararası borçlanma } \\
\text { senetlerinin toplamı }\end{array}$ & \\
\hline & $\begin{array}{l}\text { Mali kurumların borçlanma senetlerinin } \\
\text { toplamı }\end{array}$ & \\
\hline & $\begin{array}{l}\text { Mali olmayan kurumların borçlanma } \\
\text { senetlerinin toplamı }\end{array}$ & \\
\hline \multirow{2}{*}{ Erişim } & $\begin{array}{c}\text { En büyük on şirket dışındaki şirketlerin piyasa } \\
\text { değeri }\end{array}$ & Toplam değerdeki yüzdesi \\
\hline & $\begin{array}{l}\text { İç ve dış piyasalara borç veren finansal ve } \\
\text { finansal olmayan kurumların toplam sayısı }\end{array}$ & 100.000 yetişkin başına \\
\hline Etkinlik & Borsa devir hızı & $\begin{array}{l}\text { İşlem görmüş hisse senetlerinin toplam } \\
\text { değerinin borsa büyüklüğüne oranı }\end{array}$ \\
\hline
\end{tabular}

\footnotetext{
2 Ayrıntı için bkz. Svirydzenka (2016).
} 
Tablo 3 'te sunulduğu üzere bu çalışmada kullanılacak olan FK indeksi, FK'yı iki farklı boyut üzerinden ele almaktadır: Kurumlar ve piyasalar. Bu boyutlar da üç kriter üzerinden ele alınmıştır: Derinlik, erişim ve etkinlik. Ek olarak her bir kriter için o kritere gösterge olabilecek çeşitli finansal değişkenler kullanılmıştır. Örneğin finansal kurumların derinliği, özel sektör kredileri, emeklilik ve yatırım fonlarının varlıkları ve sigorta primleriyle; finansal kurumlara erişim de banka şubeleri ve bankomat sayılarıyla değerlendirilmektedir. İlaveten bu indeks, 0 (düşük FK) ile 1 (yüksek FK) arasında değerler almaktadır.

Bu çalışmada kullanılacak olan FK indeksi, diğer çalışmalardan farklı olarak, FK'yı çok boyutlu bir biçimde ele almaktadır. Böylece FK'nın karbon emisyonuna etkisi daha kapsamlı incelenebilecektir.

\subsection{Türkiye'nin İktisadi Küreselleşme ve Finansal Kalkınma İndeksleri}

Önceki alt-bölümlerde yapılarından bahsedilmiş olan iktisadi küreselleşme ve finansal kalkınma indekslerinin Türkiye'de 1980-2016 döneminde nasıl değiştiği Şekil 2'de grafiksel olarak gösterilmiştir.

\section{Şekil 2. Türkiye’nin İktisadi Küreselleşme ve Finansal Kalkınma İndekslerinin Değişimi}

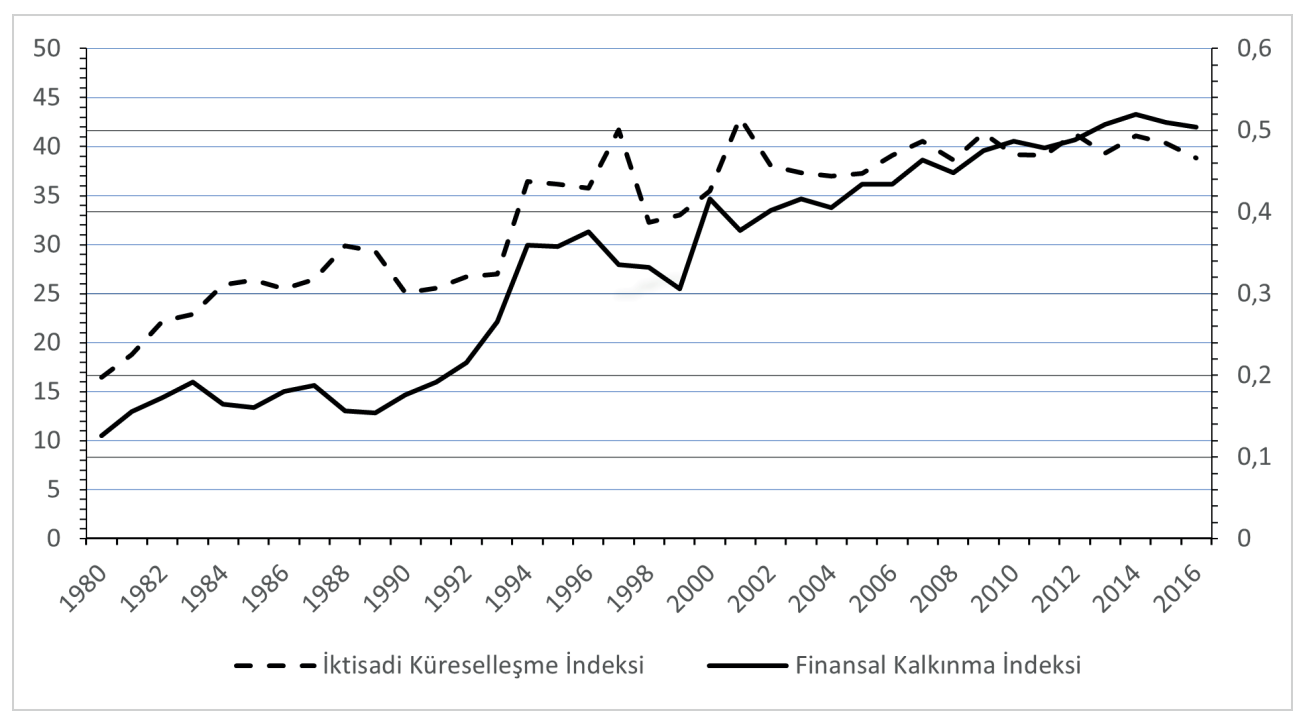

Not: Sağ eksen finansal kalkınma indeksini; sol eksen de iktisadi küreselleşme indeksini göstermektedir. Grafiğin oluşturulmasında kullanılan verilerin kaynağı Tablo 4'te gösterilmiştir.

Şekil 2'de görüldüğü üzere, Türkiye'de 1980'li yıllardan sonra iktisadi küreselleşme indeksi yükseliş eğilimine girmiştir ve FK indeksinin de 1980'lerin sonuna kadar 0,1-0,2 arasında değişen değerlerde kaldığı görülmektedir. Fakat özellikle 1990’lı yılların başından 
itibaren iktisadi küreselleşmeyle birlikte FK indeksinde de artışlar yaşanmıştır. Ayrıca bu dönem ve sonrasında, her iki göstergenin de neredeyse birlikte hareket ettiği görülmektedir. Bu grafiğe göre, Türkiye'de yaşanan iktisadi küreselleşmenin -finansal kurumların ve sistemlerin oluşturulmasını ve geliştirilmesini sağlayarak- finansal kalkınmayı tetiklediği söylenebilir. Bu durum, Mishkin’in (2009) ileri sürdüğü görüşle de uyumludur.

\section{VERİ SETİ, MODELLER VE YÖNTEM}

\subsection{Veri Seti ve Modeller}

Bu çalışmada 1980-2016 dönemi yıllık veriler kullanılmıştır. Çalışmada tahmin edilecek modeller, Denklem (1)'de; kullanılan değişkenlerin içeriği de Tablo 4'te gösterilmiştir:

$$
\begin{gathered}
K E_{t}=\rho_{1}+\delta_{1}(\dot{\mathrm{I}} G \dot{\mathrm{I}}, T G \dot{\mathrm{I}}, F G \dot{\mathrm{I}})_{t} \\
+\delta_{2} F K \dot{\mathrm{I}}_{t}+\delta_{3} G_{t}+\delta_{4} G_{t}^{2}+\delta_{5} E T_{t}+\delta_{6} I N D_{t} \\
+\delta_{7} U R B_{t}+u_{t}
\end{gathered}
$$

Denklem (1)'de de gösterildiği üzere, bu çalışmada iktisadi globalleşme indeksi ( $(G \dot{I})$ ve bunun alt-indeksleri (ticari globalleşme indeksi $(T G \dot{I})$ ve finansal globalleşme indeksi $(F G \dot{I})$ ) üzerinden üç model tahmin edilecektir ve bunlar sırasıyla Model (A), (B) ve (C) şeklinde adlandırılmıştır.

Tablo 4'te de gösterildiği üzere, iktisadi globalleşme indeksi, alt-indeksleri ve FK indeksinin $(F K \dot{I})$ yanında bu çalışmada, önceki ampirik çalışmalarda da kullanılmış olan, çeşitli kontrol değişkenleri de değerlendirilmiştir ve bunlar: Gelir $(G)$, gelirin karesi $(G 2)$, enerji tüketimi $(E T)$, sanayileşme (IND) ve kentleşmedir (URB). Gelir ve enerji tüketimi çevre kirliliğinin belirleyicisi olarak birçok çalışmada kullanılmıştır (bkz. Akçay \& Karasoy, 2018; Cetin \& Ecevit, 2017; Destek \& Ozsoy, 2015). Gelirin karesiyle birlikte modele dahil edilmesinin sebebi, çevresel Kuznets eğrisi (ÇKE) hipotezini test edebilmektir. Bu hipoteze göre gelir, karbondioksit emisyonu (çevre kirliliği) üzerinde $\cap$ şeklinde bir etkiye sahiptir. Bir başka ifadeyle gelir, belirli bir seviyeye (dönüm noktasına) kadar yükseldikçe karbon emisyonu artacaktır fakat bu belirli seviyeden (dönüm noktasından) sonra gelirde yaşanacak artışlar, karbon emisyonunu azaltacaktır (Kaika \& Zervas, 2013, s. 1394). Bu yaklaşımda, tahmin edilen dönüm noktasının araştırmacı ve politika koyucularına geçerli bulgular sağlayabilecek nitelikte ve anlamlı olması önemlidir (Brown \& McDonough, 2016, s. 455). Bu yüzden ÇKE hipotezini test etmek için, Halicioglu (2009) çalışmasına benzer şekilde, şu kriterler göz önünde bulundurulacaktır: (i) Gelirin ve gelirin karesinin katsayıları (istatistiksel olarak) anlamlı mı? (ii) Anlamlı ise hesaplanan dönüm noktaları, örneklem dönemi gelir zaman serisinin değişim aralığının (range) içinde bir değere sahip mi? Eğer bu kriterlerden herhangi birisi geçerli değilse ilgili model için ÇKE hipotezi reddedilecektir.

Enerji tüketimi (ET) de karbondioksit emisyonunun ana belirleyicilerinden birisi olarak kabul edildiği için (bkz. Özdemir \& Koç, 2020; Gokmenoglu ve ark., 2020; Dar \& Asif, 
2018; Akçay \& Karasoy, 2018) bu araştırmanın modellerine (kontrol değişkeni olarak) eklenmiştir. Sanayileşme (IND) ve kentleşme (URB), bu araştırmaya dahil edilen diğer kontrol değişkenleridir. Türkiye üzerine yapılmış çalışmalarda, bu değişkenlerden ikisi birden (bkz. Pata, 2018) ya da en az birisi (bkz. Destek \& Ozsoy, 2015; Ozatac ve ark., 2017) tahmin edilen modellere dahil edilmiştir. Ayrıca 1980 sonrasında Türkiye'de iktisadi serbestleşmeyle birlikte sanayileşme ve kentleşme süreçlerinin de hızlandığı düşünülürse bu değişkenlerin tahmin edilecek modellerde kullanılması bu süreçlerin de karbon emisyonunu nasıl etkilediği konusunda ek bulgular sunabilir.

Tablo 4: Modellerde Kullanılan Değişkenlerin İçeriği

\begin{tabular}{|c|c|c|}
\hline Değişkenler & Değişkenlerin İçeriği & Değişkenlerin Kaynă̆ı \\
\hline$K E$ & $\begin{array}{c}\text { Karbondioksit emisyonu } \\
\text { (kişi başına milyon ton karbondioksit) }\end{array}$ & $\begin{array}{l}\text { British Petroleum (BP) veri tabanı } \\
\text { (BP Statistical Review of World Energy, 2019) }\end{array}$ \\
\hline$\dot{I} G \dot{I}$ & İktisadi globalleşme indeksi & \multirow{3}{*}{$\begin{array}{c}\text { KOF Küreselleşme İndeksi } \\
\text { (KOF Swiss Economic Institute, 2020) }\end{array}$} \\
\hline$T G \dot{I}$ & Ticari globalleşme indeksi & \\
\hline$F G \dot{I}$ & Finansal globalleşme indeksi & \\
\hline$F K \dot{I}$ & Finansal kalkınma indeksi & $\begin{array}{l}\text { Uluslararası Para Fonu'nun (IMF) finansal } \\
\text { kalkınma indeksi veri tabanı } \\
\text { (IMF, 2020) }\end{array}$ \\
\hline$G, G 2$ & $\begin{array}{c}\text { Gelir, gelirin karesi } \\
\text { (kişi başına } 2010 \text { ABD doları cinsinden } \\
\text { GSYH) }\end{array}$ & $\begin{array}{c}\text { Dünya Bankası'nın Dünya Kalkınma } \\
\text { Göstergeleri veri tabanı } \\
\text { (The World Bank, 2020) }\end{array}$ \\
\hline$E T$ & $\begin{array}{c}\text { Birincil enerji tüketimi } \\
\text { (kişi başına milyon ton eşdeğer petrol) }\end{array}$ & $\begin{array}{c}\text { BP veri tabanı (BP Statistical Review of World } \\
\text { Energy, 2019) }\end{array}$ \\
\hline$I N D$ & $\begin{array}{l}\text { Sanayileşme (imalat sektöründe yaratılan } \\
\text { katma değer, kişi başına } 2010 \text { ABD doları) }\end{array}$ & \multirow[t]{2}{*}{$\begin{array}{l}\text { Dünya Kalkınma Göstergeleri veri tabanı } \\
\text { (The World Bank, 2020) }\end{array}$} \\
\hline$U R B$ & Kentleşme (kent nüfusunun büyüme oranı, \%) & \\
\hline
\end{tabular}

Not: Dünya Kalkınma Göstergeleri veri tabanından (The World Bank, 2020) alınmış nüfus zaman serisi ile $K E$, ET ve $I N D$ değişkenleri kişi başına dönüştürülmüştür.

\subsection{Yöntem: Eş-bütünleşmenin Genişletilmiş ARDL Sınır Testleriyle İncelenmesi ${ }^{3}$}

Bu araştırmada, Pesaran ve ark. (PSS) (2001) tarafından oluşturulmuş olan tipik ARDL sınır testlerinin yanında McNown ve ark. (MSG) (2018) ve Sam ve ark. (SMG) (2019) çalışmalarında ileri sürülmüş olan genişletilmiş (augmented) ARDL sınır testi yaklaşımı da kullanılacaktır. Genişletilmiş ARDL yaklaşımının avantajları ve bu çalışmada kullanılacak

\footnotetext{
${ }^{3} \mathrm{Bu}$ kısımda, ARDL ve genişletilmiş ARDL yaklaşımları genel hatlarıyla aktarılmıştır. Bu yöntemler hakkında daha fazla bilgiye MSG (2018), PSS (2001) ve SMG (2019) çalışmalarında ulaşılabilir.
} 
olmasının nedenleri şöyle sıralanabilir: $(i)$ Bu yöntem küçük örnekleme sahip modellere de uygulanabilir, (ii) açıklayıcı değişkenlerin yanında açıklanan değişken de düzeyde durağan $(I(0))$ ya da birinci farkında durağan $(I(1))$ olabilir fakat kullanılan değişkenler arasında ikinci farkta durağan olan (I(2)) zaman serileri olmamalıdır, (iii) içsellik, modellerin tahmini açısından anlamlı bir soruna sebep olmamaktadır, (iv) eş-bütünleşmenin kabul edilmesi durumunda, kısa ve uzun dönemlerde, açıklayıcı değişkenlerin açıklanan değişkeni nasıl etkilediği eş zamanlı olarak tahmin edilebilir (bkz. MSG, 2018; PSS, 2001; Pesaran \& Shin, 1995).

$\mathrm{Bu}$ çalışmada kullanılacak olan ARDL yaklaşımında iki aşama söz konusudur: Değişkenlerin uzun dönemde birlikte hareket edip etmediklerinin (eş-bütünleşmenin) sınır testleriyle sınanması ve eğer eş-bütünleşme varsa açıklayıcı değişkenlerin bağımlı değişkeni kısa ve uzun dönemlerde nasıl etkilediğinin tahmin edilmesi. Birinci aşamada, eş-bütünleşme testlerinin uygulanabilmesi için aşağıda gösterilmiş olan hata düzeltme modelinin tahmin edilmesi gerekmektedir:

$$
\begin{gathered}
\Delta \ln K E_{t}=\rho_{1}+\sum_{i=1}^{p} \rho_{i} \Delta \ln K E_{t-i}+\sum_{m=0}^{u} \rho_{m} \Delta \ln (\dot{\mathrm{I}} G \dot{\mathrm{I}}, T G \dot{\mathrm{I}}, F G \dot{\mathrm{I}})_{t-m}+\sum_{z=0}^{b} \rho_{z} \Delta \ln F K \dot{\mathrm{I}}_{t-z} \\
+\sum_{j=0}^{q} \rho_{j} \Delta \ln G_{t-j}+\sum_{k=0}^{r} \rho_{k} \Delta \ln G_{t-k}^{2}+\sum_{l=0}^{s} \rho_{l} \Delta \ln E T_{t-l}+\sum_{v=0}^{e} \rho_{v} \Delta \ln I N D_{t-v}+\sum_{w=0}^{a} \rho_{w} \Delta \ln U R B_{t-w} \\
+\delta_{1} \ln K E_{t-1}+\delta_{2} \ln (\dot{\mathrm{I}} G \dot{\mathrm{I}}, T G \dot{\mathrm{I}}, F G \dot{\mathrm{I}})_{t-1}+\delta_{3} \ln F K \dot{\mathrm{I}}_{t-1}+ \\
\delta_{4} \ln G_{t-1}+\delta_{5} \ln G_{t-1}^{2}+\delta_{6} \ln E T_{t-1}+\delta_{7} \ln I N D_{t-1}+\delta_{8} \ln U R B_{t-1}+\mu_{t}
\end{gathered}
$$

Denklem (2)'de iktisadi globalleşmeyi $(\dot{I} G \dot{I})[$ Model $(A)]$, ticari globalleşmeyi (TGI) $[$ Model $(B)]$ ve finansal globalleşmeyi $(F G \dot{I})[$ Model $(C)]$ içeren modeller bir arada gösterilmektedir. Denklem (2)'de $\rho_{1}$, sabit terimdir. $\rho_{\mathrm{i}, \mathrm{m}, \mathrm{z}, \mathrm{j}, \mathrm{k}, \mathrm{l}, \mathrm{v}, \mathrm{w}} \mathrm{k}$ ssa dönem; $\delta_{1, . ., 8}$ ise uzun dönem katsayılarını göstermektedir. Ayrıca $\Delta$ sembolü, fark işlemcisidir. ln, değişkenlerin logaritmalarının kullanıldığını belirtmektedir. Katsayıların optimum gecikme uzunlukları ( $p$, $u, b, q, r, s, e, a)$ belirlenirken Schwarz bilgi kriteri (SIC); modellerin tahmininde de kısıtlamasız sabitli fakat trendin olmadığı Durum-III (Case-III) dikkate alınmıştır. Son olarak, maksimum gecikme uzunluğu, yıllık verilerin kullanılması sebebiyle, 1 olarak seçilmiştir.

Denklem (2)'den yola çıkarak ifade etmek gerekirse PSS (2001) tarafindan öne sürülen eş-bütünleşme süreci iki farklı sınır testi üzerinden sınanmaktadır: F- ve t- testleri. Bu yaklaşıma göre F-testi, bağımlı ve bağımsız değişkenlerin birinci gecikmeli değerlerinin katsayılarını $\left(\delta_{1 . .8}\right)$ değerlendirirken t-testi de sadece açıklanan değişkenin birinci gecikmeli değerinin katsayısını $\left(\delta_{1}\right)$ dikkate almaktadır. Bu testlerin boş ve alternatif hipotezleri de şu şekildedir: F-testi için $H_{0}: \delta_{1}=\delta_{2}=\delta_{3}=\delta_{4}=\delta_{5}=\delta_{6}=\delta_{7}=\delta_{8}=0, H_{1}: \delta_{1} \neq \delta_{2} \neq \delta_{3} \neq \delta_{4} \neq \delta_{5} \neq \delta_{6} \neq$ 
$\delta_{7} \neq \delta_{8} \neq 0$ ve t-testi için $H_{0}: \delta_{1}=0, H_{1}: \delta_{1} \neq 0$ 'dır. Tipik olarak bu testlerin uygulanmas 1 sonucunda elde edilen istatistikler, yine PSS (2001) tarafından bu testler için hesaplanmış olan, alt ve üst sınır kritik değerleriyle karşılaştırılacaktır. Eğer elde edilen test istatistikleri üst-sınır kritik değerlerinden (mutlak değerde) büyükse bu testlerin boş hipotezleri reddedilecek ve uzun dönemde modellerdeki değişkenlerin birlikte hareket ettiği sonucuna varılacaktır. Fakat MSG (2018, s. 1512), PSS (2001, s. 294-295) ve SMG (2019, s. 130) çalışmalarında belirtildiği üzere bu yaklaşımda iki farklı bozuk (dejenere) durum ortaya çıkabilmektedir ve bu dejenere durumlar da test sonuçlarının göstermiş olduğu eşbütünleşme sonucunu geçersiz kılabilmektedir. Bu bozuk durumlar şu şekilde özetlenebilir:

Bozuk Durum \#1: Bu durum, açıklayıcı değişkenlerin gecikmeli değerlerinin anlamsız $\left(\delta_{2}=\delta_{3}=\delta_{4}=\delta_{5}=\delta_{6}=\delta_{7}=\delta_{8}=0\right)$ fakat açıklanan değişkenin gecikmeli değerinin anlaml olmasıyla $\left(\delta_{1} \neq 0\right)$ ortaya çıkmaktadır. Bozuk Durum \#2: Bu durum da açıklayıcı değişkenlerin gecikmeli değerlerinin anlamlı $\left(\delta_{2} \neq \delta_{3} \neq \delta_{4} \neq \delta_{5} \neq \delta_{6} \neq \delta_{7} \neq \delta_{8} \neq 0\right)$, açıklanan değişkenin gecikmeli değerinin anlamsız olması $\left(\delta_{1}=0\right)$ ile ortaya çıkmaktadır.

PSS (2001) çalışmasına göre Bozuk Durum \#2 -yukarıda da açıklanmış olan- bağımlı değişkenin gecikmeli değerini dikkate alan t-testi ile çözülebilirken, Bozuk Durum \#l'i bertaraf edebilmek içinse açıklanan değişkenin birinci dereceden entegre (birinci farkında durağan - I(1)) olması gerekmektedir. Ama birim-kök testleri, bu çalışmada olduğu gibi, çelişkili sonuçlar verebilmektedir. Bu yüzden, bu varsayım da geçerliliğini kaybedebilmektedir. Bu durumun üstesinden gelebilmek için MSG (2018) tarafindan öz çıkarım (bootstrap) ARDL olarak da adlandırılan ve sonrasında SMG (2019) tarafından genişletilmiş ARDL olarak isimlendirilen bir sınır testi daha önerilmiştir. Bu $\mathrm{F}_{\mathrm{Açılkayı1}}$-testi, F- ve t- testlerinden farklı olarak, sadece açıklayıcı değişkenlerin birinci gecikmelerini $\left(\delta_{2, \ldots, 8}\right)$ değerlendirmektedir. Bu testin boş ve alternatif hipotezleri şöyledir: $H_{0}: \delta_{2}=\delta_{3}=\delta_{4}=$ $\delta_{5}=\delta_{6}=\delta_{7}=\delta_{8}=0, H_{1}: \delta_{2} \neq \delta_{3} \neq \delta_{4} \neq \delta_{5} \neq \delta_{6} \neq \delta_{7} \neq \delta_{8} \neq 0$. Eğer test sonucunda elde edilen istatistik değeri, SMG (2019) tarafından hesaplanmış olan üst-sınır kritik değerinden yüksekse, boş hipotez reddedilecektir.

Özet olarak, eş-bütünleşme için yukarıda tanımlanmış olan üç test (F-, t- ve $\mathrm{F}_{\text {Açıklayıc1 }}{ }^{-}$ testleri) uygulanacaktır. Eğer üç testin hepsi de anlamlıysa modellerde kullanılan değişkenler arasında eş-bütünleşme olduğu sonucuna varılacaktır. Aksi durumlardaysa eş-bütünleşme olmadığı sonucuna ulaşılacaktır. Son aşamada, eş-bütünleşmenin kabul edilmesi durumunda, açıklayıcı değişkenlerin açıklanan değişkene olan uzun ve kısa dönem etkileri -her üç model için de- yine ARDL yaklaşımıyla tahmin edilecektir.

\section{EKONOMETRIK BULGULAR}

Eş-bütünleşme testlerinin uygulanmasından önce modellerde kullanılan zaman serilerinin kaçıncı dereceden entegre oldukları kararlaştırılmalıdır. Bu kapsamda, bu çalışmada, Lee \& 
Strazicich (LS) $(2003,2013)$ tarafından geliştirilmiş olan, tek ve iki kırılmaya izin veren birim-kök testleri kullanılmıştır. Bu testlerin sonuçları Tablo 5’te gösterilmiştir.

Tablo 5: Birim-kök Testlerinin Sonuçları

\begin{tabular}{|c|c|c|c|c|c|}
\hline \multicolumn{3}{|c|}{ Tek Kırılmalı LS (2013) Testi } & \multicolumn{3}{|c|}{ İki Kırılmalı LS (2003) Testi } \\
\hline Değișkenler & $\mathbf{T}_{\mathrm{B} 1}$ & Test İstatistiği & $\mathbf{T}_{\mathbf{B 1}}$ & $\mathbf{T}_{\mathbf{B} 2}$ & Test İst. \\
\hline $\ln K E$ & 1999 & $-5,281 * * *(4)$ & 1989 & 2005 & $-4,504(0)$ \\
\hline $\ln \dot{I} G \dot{I}$ & 1998 & $-4,354 * *(0)$ & 1984 & 1993 & $-5,004(0)$ \\
\hline $\ln T G \dot{I}$ & 1999 & $-4,286^{*}(1)$ & 1984 & 1993 & $-5,731(1)$ \\
\hline $\ln F G \dot{I}$ & 1998 & $-4,226^{*}(0)$ & 1998 & 2007 & $-5,067(2)$ \\
\hline $\ln F K \dot{I}$ & 1992 & $-4,151 *(2)$ & 1986 & 1992 & $-6,582 * *(2)$ \\
\hline $\ln G$ & 1999 & $-5,049 * * *(2)$ & 1993 & 1999 & $-4,456(1)$ \\
\hline $\ln E T$ & 1987 & $-3,943 *(0)$ & 1985 & 1999 & $-5,072(2)$ \\
\hline $\ln I N D$ & 1999 & $-4,848 * *(2)$ & 1993 & 1999 & $-5,108(2)$ \\
\hline $\ln U R B$ & 1990 & $-5,389 * * *(4)$ & 1989 & 1999 & $-10,929 * * *(4)$ \\
\hline$\triangle \ln K E$ & - & - & 1983 & 1989 & $-6,056 * * *(0)$ \\
\hline$\Delta \ln \dot{I} G \dot{I}$ & - & - & 1983 & 1990 & $-7,176 * * *(0)$ \\
\hline$\triangle \ln T G \dot{I}$ & 1984 & $-5,543 * * *(0)$ & 1990 & 1997 & $-5,635^{* * *}(0)$ \\
\hline$\triangle \ln F G \dot{I}$ & 1987 & $-8,749 * * *(0)$ & 1983 & 1990 & $-8,033 * * *(0)$ \\
\hline$\triangle \ln F K \dot{I}$ & - & - & - & - & - \\
\hline$\Delta \ln G$ & - & - & 1983 & 2002 & $-6,350 * * *(0)$ \\
\hline$\triangle \ln E T$ & 1983 & $-6,496^{* * *}(0)$ & 1983 & 1986 & $-6,739 * * *(0)$ \\
\hline$\triangle \ln I N D$ & - & - & 1983 & 2001 & $-6,395 * * *(0)$ \\
\hline$\triangle \ln U R B$ & - & - & - & - & - \\
\hline
\end{tabular}

Not: $\Delta$ birinci farktır. Düzeydeki değişkenlerde hem sabitte hem de eğilimde (trend) yapısal kırılmayı içeren model dikkate alınmıştır. Birinci farkı alınmış değişkenlerde, sadece sabitte yapısal kırılmayı içeren model kullanılmıştır. ***, ** ve * işaretleri sırasıyla \%1, \%5 ve $\% 10$ anlamlılık düzeylerini göstermektedir. $\mathrm{T}_{\mathrm{B} 1}$ ve $\mathrm{T}_{\mathrm{B} 2}$ kırılma yıllarıdır. Parantez içindeki rakamlar gecikme uzunluklarıdır.

Tablo 5'teki bulgulara göre, her iki test sonuçları da değerlendirildiğinde, modellerde kullanılmış değişkenlerin arasında ikinci farkında durağan [I(2)] olan bir değişken olmadığı görülmektedir. Bir başka ifadeyle, modellerde ARDL eş-bütünleşme yaklaşımı kullanılabilir. Testlerin sonuçları, kırılma dönemleri olarak farklı yılları göstermektedir. Ayrıca tek kırılmalı birim-kök test sonuçlarına göre bu çalışmanın açıklanan değişkeni olan karbon emisyonu düzeyde durağandır (I(0)'dır). Bu bulgu, açıklayıcı değişkenin $I(0)$ olmasına da izin veren, genişletilmiş ARDL sınır testi metodunun kullanılmasının gerekli olduğunu göstermektedir.

Genişletilmiş ARDL sınır testlerinin sonuçları ve tahmin edilmiş modellere ait tanısal testlerin sonuçları Tablo 6'da sunulmuştur. Bu sonuçlara göre tahmin edilmiş modellerin hepsinde üç sınır testi (F-, t- ve $\mathrm{F}_{\mathrm{Açıklayıcı}}$-testleri) de anlamlıdır. Bu sonuçlar, bütün modellerde (Model $(A)$, (B) ve $(C))$ kullanılmış olan değişkenlerin uzun dönemde birlikte hareket ettiğini göstermektedir. Tanısal test sonuçları da bu çalışmada tahmin edilmiş olan 
modellerin, ekonometrik ve istatistiksel açıdan problemli olmadığını göstermektedir. Eşbütünleşme söz konusu olduğu için modellerdeki bağımsız değişkenlerin, açıklanan değişkeni uzun ve kısa dönemlerde nasıl etkiledikleri tahmin edilebilir. Bu tahmin sonuçları da Tablo 7'de raporlanmıştır.

Tablo 6: Genişletilmiş ARDL Sınır Testleri ve Tanısal Test Sonuçları

\begin{tabular}{|c|c|c|c|}
\hline \multicolumn{4}{|c|}{ Model (A), Gecikme Değerleri $(1,1,1,0,0,1,1,1)$} \\
\hline F-istatistiği $=8,5474 * * *$ & t-istatistiği $=-6,545 * * *$ & \multicolumn{2}{|c|}{$\mathrm{F}_{\text {Açıklayıc1 }}$-istatistiğ $\mathrm{i}=9,735 * * *$} \\
\hline Tanisal Testler: & & Test değeri & p-değeri \\
\hline Breusch-Godfrey Serisel Kor. LM Testi & & 0,588 & 0,443 \\
\hline Ramsey RESET Testi & & 1,981 & 0,174 \\
\hline Jarque-Bera Normallik Testi & & 1,389 & 0,499 \\
\hline ARCH Değișen Varyans Testi & & 0,095 & 0,758 \\
\hline CUSUM/CUSUMSQ & & Stabil & Stabil \\
\hline $\mathrm{R}^{2}$ & & \multicolumn{2}{|c|}{0,996} \\
\hline Düzeltilmiş $\mathrm{R}^{2}$ & & \multicolumn{2}{|c|}{0,994} \\
\hline F-istatistiği & & \multicolumn{2}{|c|}{$437,074 * * *$} \\
\hline
\end{tabular}

\begin{tabular}{|c|c|c|c|}
\hline \multicolumn{4}{|l|}{ Model $(\mathrm{B}),(\mathbf{1}, \mathbf{0}, \mathbf{1}, \mathbf{0}, \mathbf{0}, \mathbf{0}, \mathbf{0 , 0})$} \\
\hline $\mathrm{F}$-istatistiğ $\mathrm{i}=8,414 * * *$ & t-istatistiğ $\mathrm{i}=-6,592 * * *$ & \multicolumn{2}{|c|}{$\mathrm{F}_{\text {Açıklayıc1 }}$-istatistiğ $\mathrm{i}=8,967 * * *$} \\
\hline Tanisal Testler: & & Test değeri & $p$-değeri \\
\hline Breusch-Godfrey Serisel Kor. LM Testi & & 0,412 & 0,521 \\
\hline Ramsey RESET Testi & & 0,376 & 0,545 \\
\hline Jarque-Bera Normallik Testi & & 1,492 & 0,474 \\
\hline ARCH Değișen Varyans Testi & & 0,205 & 0,651 \\
\hline CUSUM/CUSUMSQ & & Stabil & Stabil \\
\hline $\mathrm{R}^{2}$ & & \multicolumn{2}{|c|}{0,994} \\
\hline Düzeltilmiş $\mathrm{R}^{2}$ & & \multicolumn{2}{|c|}{0,992} \\
\hline F-istatistiği & & \multicolumn{2}{|c|}{$504,633 * * *$} \\
\hline \multicolumn{4}{|l|}{ Model $(C),(1,1,1,0,0,1,0,1)$} \\
\hline F-istatistiğ $\mathrm{i}=10,1004^{* * *}$ & t-istatistiği $=-6,763 * * *$ & \multicolumn{2}{|c|}{$\mathrm{F}_{\text {Açıklayıc1 }}$-istatistiğ $\mathrm{i}=11,463 * * *$} \\
\hline Tanisal Testler: & & Test değeri & p-değeri \\
\hline Breusch-Godfrey Serisel Kor. LM Testi & & 0,242 & 0,623 \\
\hline Ramsey RESET Testi & & 1,138 & 0,298 \\
\hline Jarque-Bera Normallik Testi & & 1,445 & 0,486 \\
\hline ARCH Değişen Varyans Testi & & 0,117 & 0,733 \\
\hline CUSUM/CUSUMSQ & & Stabil & Stabil \\
\hline $\mathrm{R}^{2}$ & & \multicolumn{2}{|c|}{0,996} \\
\hline Düzeltilmiş $\mathrm{R}^{2}$ & & \multicolumn{2}{|c|}{0,994} \\
\hline F-istatistiği & & \multicolumn{2}{|c|}{$485,502 * * *$} \\
\hline
\end{tabular}

Not: Modellerin tahmininde, kısıtlamasız sabitli ve trendin olmadığı üçüncü durum (Case-III) dikkate alınmıştır. Bütün modellerde maksimum gecikme uzunluğu 1 olarak belirlenmiş ve değişkenlerin optimum gecikme uzunluklarının seçiminde Schwarz bilgi kriteri (SIC) kullanılmıștır. Parantez içindeki değerler, modellerdeki her bir değișken için belirlenmiș olan optimum gecikme değerlerini göstermektedir.

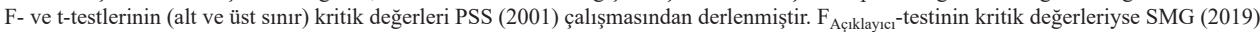
çalışmasından alınmıştır. *** sembolü $1 \%$ düzeyinde anlamlılığı göstermektedir. 
Tablo 7: ARDL Modelleri Katsayı Tahmin Sonuçları

\section{A) Uzun dönem}

\begin{tabular}{|c|c|c|c|}
\hline Bağımsız Değişkenler & Model (A) & Model (B) & Model (C) \\
\hline $\ln \dot{I} G \dot{I}$ & $\begin{array}{c}0,055 \\
(0,508)\end{array}$ & - & - \\
\hline $\ln T G \dot{I}$ & - & $\begin{array}{c}-0,123 * * \\
(0,024)\end{array}$ & - \\
\hline $\ln F G \dot{I}$ & - & - & $\begin{array}{c}0,103 \\
(0,114)\end{array}$ \\
\hline $\ln F K \dot{I}$ & $\begin{array}{c}0,021 \\
(0,659)\end{array}$ & $\begin{array}{c}0,106 * * \\
(0,022)\end{array}$ & $\begin{array}{c}0,001 \\
(0,968)\end{array}$ \\
\hline $\ln G$ & $\begin{array}{l}7,651 * * \\
(0,043)\end{array}$ & $\begin{array}{l}6,085^{*} \\
(0,059)\end{array}$ & $\begin{array}{c}6,116 \\
(0,113)\end{array}$ \\
\hline $\ln G 2$ & $\begin{array}{c}-0,411 * * \\
(0,036)\end{array}$ & $\begin{array}{c}-0,369 * * \\
(0,026)\end{array}$ & $\begin{array}{l}-0,346^{*} \\
(0,083)\end{array}$ \\
\hline $\ln E T$ & $\begin{array}{c}0,575 * * * \\
(0,004)\end{array}$ & $\begin{array}{c}0,571 * * * \\
(0,004)\end{array}$ & $\begin{array}{c}0,526^{* * * *} \\
(0,005)\end{array}$ \\
\hline $\ln I N D$ & $\begin{array}{c}0,219 \\
(0,510)\end{array}$ & $\begin{array}{c}0,793 * * \\
(0,021)\end{array}$ & $\begin{array}{l}0,521 * \\
(0,093)\end{array}$ \\
\hline $\ln U R B$ & $\begin{array}{c}0,172 * * \\
(0,019)\end{array}$ & $\begin{array}{c}0,178 * * * \\
(0,008)\end{array}$ & $\begin{array}{c}0,162 * * \\
(0,021)\end{array}$ \\
\hline$G^{*}$ & $11.023,514$ & $3.809,516$ & - \\
\hline \multicolumn{4}{|l|}{ 7B) Kisa dönem } \\
\hline Sabit & $\begin{array}{c}-37,684 * * * \\
(0,000)\end{array}$ & $\begin{array}{c}-34,484 * * * \\
(0,000)\end{array}$ & $\begin{array}{c}-33,127 * * * \\
(0,000)\end{array}$ \\
\hline$\Delta \ln F K \dot{I}_{\mathrm{t}}$ & $\begin{array}{c}0,156^{* * *} \\
(0,000)\end{array}$ & - & $\begin{array}{c}0,142 * * * \\
(0,000)\end{array}$ \\
\hline$\Delta \ln G_{\mathrm{t}}$ & $\begin{array}{c}18,951 * * * \\
(0,000)\end{array}$ & - & $\begin{array}{c}17,974 * * * \\
(0,000)\end{array}$ \\
\hline$\Delta \ln G 2_{\mathrm{t}}$ & $\begin{array}{c}-1,103 * * * \\
(0,000)\end{array}$ & $\begin{array}{c}-0,384 * * * \\
(0,000)\end{array}$ & $\begin{array}{c}-1,056^{* * *} \\
(0,000)\end{array}$ \\
\hline$\Delta \ln I N D_{\mathrm{t}}$ & $\begin{array}{c}0,848 * * * \\
(0,000)\end{array}$ & - & $\begin{array}{c}1,011 * * * \\
(0,000)\end{array}$ \\
\hline$\Delta \ln U R B_{\mathrm{t}}$ & $\begin{array}{c}0,079 * * \\
(0,037)\end{array}$ & - & - \\
\hline$E C T_{\mathrm{t}-1}$ & $\begin{array}{c}-0,892 * * * \\
(0,000)\end{array}$ & $\begin{array}{c}-0,986^{* * *} \\
(0,000)\end{array}$ & $\begin{array}{c}-0,901 * * * \\
(0,000)\end{array}$ \\
\hline
\end{tabular}

Not: Parantez içindeki sayılar p-değerlerini göstermektedir. ***, ** ve * sırasıyla \%1, \%5 ve \%10 düzeylerinde anlamlılığı göstermektedir. $G^{*}$ uzun dönem katsayılarıyla ve $G^{*}=e^{\left(-\left(\frac{\delta_{3}}{2 \delta_{4}}\right)\right)}$ formülüyle hesaplanmıș gelirin dönüm noktasıdır. Formül, Denklem (1)'e göre gösterilmiştir. ECT hata düzeltme terimidir. 
Tablo 7'nin A panelinde (7A), uzun dönem sonuçları; B panelinde (7B) de kısa dönem bulguları gösterilmektedir. Uzun dönem sonuçlarına göre iktisadi globalleşme $(\dot{I} G \dot{I})$ ve finansal globalleşmenin $(F G \dot{I})$ etkileri anlamsızken ticari globalleşmenin $(T G \dot{I})$ etkisi (Model (B)) negatiftir. Bu sonuca göre ticari globalleşme indeksinde yaşanacak olan \%1'lik bir artış karbondioksit emisyonunu (KE) \%0,12 kadar azaltacaktır. Bu bulgu, Ozatac ve ark. (2017), Cetin \& Ecevit (2017) ve Ozturk \& Acaravci (2013) çalışmalarındaki bulgularla çelişmekte fakat Destek \& Ozsoy (2015) çalışmasının sonucunu doğrulamaktadır. Bu çelişkinin ana sebebi olarak, farklı bir örneklem döneminin ve ticari serbestleşme göstergesinin seçilmiş olması gösterilebilir.

Yine aynı tablodaki uzun ve kısa dönem sonuçları (7A ve 7B panelleri), FK indeksinin uzun dönemde sadece Model (B)'de; kısa dönemde de diğer modellerde (Model (A) ve Model $(C)$ ) karbon emisyonunu arttırdığını göstermektedir. Örneğin, FKİ'de yaşanacak olan \%1'lik bir artış (azalış) uzun dönemde Model (B)'de karbon emisyonunu \%0,11 kadar arttıracakken (azaltacakken) kısa dönemde (Model (A) ve (C)'de) karbon emisyonunu, sırasıyla, \%0,16 ve \%0,14 kadar arttıracaktır (azaltacaktır). Bu sonuç, Karasoy (2019), Pata (2018) ve Cetin \& Ecevit (2017) çalışmalarındaki bulgularla uyumluyken Gokmenoglu ve ark. (2020), Dar \& Asif (2018) ve Akçay \& Karasoy (2018) çalışmalarıyla uyumsuzdur. Bunun ana sebebi olarak, bu çalışmalarda tek boyutlu değişkenler FK'nın göstergesi olarak kullanılmışken bu araştırmada çok boyutlu bir FK indeksinin kullanılmış olması gösterilebilir.

Tablo 7'deki gelir $(G)$ ve gelirin karesine (G2) ait uzun dönem katsayıları incelendiğinde, Model (A) ve $(B)$ 'de bu katsayıların anlamlı ve sırasıyla pozitif ve negatif işaretlere sahip olduğu fakat Model $(C)$ 'de gelirin katsayısının anlamsız olduğu görülmektedir. İlaveten, Model $(A)$ ve $(B)$ 'deki anlamlı katsayılar üzerinden gelirin dönüm noktası $\left(G^{*}\right)$ hesaplandığında da sadece Model (A)'nın hesaplanan dönüm noktasının (11.023 ABD dolarl) gelir değişkeninin değişim aralığında ${ }^{4}$ kaldığı sonucuna ulaşılmıştır. Bu bulgular 1şığında, ÇKE hipotezinin sadece Model (A)'da geçerli olduğu ve diğer modellerde geçerli olmadığı sonucu çıkarılabilir. Bir başka ifadeyle tahmin edilen üç modelin ikisinde ÇKE hipotezi geçerli değildir. Ek olarak bu sonuç, Türkiye'deki gelir düzeyinin, çevresel bir bilinç oluşturarak çevresel kirliliği azaltacak düzeylere henüz ulaşamadığına da işaret etmektedir.

Tablo 7'deki diğer sonuçlara göre: (1) Enerji tüketimi uzun dönemde, beklendiği gibi, karbon emisyonunu arttırmaktadır. (2) Türkiye'deki sanayileşme ve kentleşme süreçleri kısa dönemde ve/veya uzun dönemde karbondioksit salımını arttırmaktadır. (3) Hata düzeltme

\footnotetext{
4 1980-2016 dönemi için gelir düzeyinin $(G)$ aldığı maksimum değer 14.063 ve minimum değer de 4.987 ABD dolarıdır (2010 fiyatlarıla).
} 
teriminin katsayısı, üç modelde de istatistiksel olarak anlamlıdır ve beklenen değerler arasında yer almaktadır (katsayıların tümü 0 ile -1 arasında değerler almıştır).

\section{SONUÇ VE POLITIKA ÖNERÍLERİ}

Bu çalışmada, 1980-2016 dönemi temel alınarak, başta iktisadi küreselleşme ve finansal kalkınma olmak üzere gelir, enerji tüketimi, sanayileşme ve kentleşmenin Türkiye'deki karbondioksit emisyonunu nasıl etkiledikleri ÇKE hipotezi çerçevesinde incelenmiştir. $\mathrm{Bu}$ araştırmanın önceki çalışmalardan farkı, iktisadi küreselleşme ve finansal kalkınmayı tek boyutlu değişkenler yerine çok boyutlu indeksler üzerinden değerlendirmesidir. Yöntem olarak genişletilmiş ARDL yaklaşımının kullanıldığı bu araştırmanın bulguları şunlardır: 1) Uzun dönemde ticari küreselleşme karbondioksit emisyonunu azaltmaktadır fakat iktisadi ve finansal küreselleşmenin karbon emisyonuna anlamlı bir etkisi yoktur. 2) Kısa dönemde iktisadi, ticari ve finansal küreselleşme karbondioksit emisyonunu etkilememektedir. 3) Finansal kalkınma uzun veya kısa dönemde karbondioksit emisyonunu arttırmaktadır. 4) Türkiye'de karbon salımı için ÇKE hipotezi geçerli değildir. 5) Uzun dönemde enerji tüketimi, sanayileşme ve kentleşme karbon emisyonunu arttırmaktadır. 6) Kısa dönemde de sanayileşme ve/veya kentleşmenin karbon salımı üzerinde arttırıcı etkisi/etkileri vardır.

Bu bulgular doğrultusunda çeşitli politika önerileri sunulabilir. Öncelikle Türkiye'deki iktisadi küreselleşme süreci çevresel bozulmayı olumsuz etkilememiş ve ticari küreselleşme de çevresel bozulmanın azalmasına katkıda bulunmuştur. Bu açıdan değerlendirildiğinde, ticari küreselleşmenin sadece teknik etki yoluyla değil aynı zamanda ticari ortak sayısındaki artışla beraber piyasalardaki rekabeti ve böylece enerji tüketimindeki etkinliği de arttırdığ öne sürülebilir. Bundan dolayı Türkiye'deki politika koyucuları, dünya ekonomisine entegre olma sürecinde sadece ticaret hacmini değil aynı anda Türkiye'nin ticaret partneri sayısını da arttırmaya yönelik politikalar takip etmelidir.

Finansal kalkınma, Türkiye'deki karbon emisyonunu arttırmaktadır. Bu durumu bertaraf edebilmek için Türkiye'deki finansal kurumların ve piyasaların sürdürülebilir kalkınmaya olanak verecek şekilde yenilenmesi gerekmektedir. Bu kapsamda finansal kurumlar, çevre dostu üretim tekniklerinin ve ürünlerin kullanımını kolaylaştıracak teşvikler sunabilmeli ve finansal piyasalar da -bu teşviklere erişimi kolaylaştıracak biçimde- düzenlenmelidir. Özetle sadece kredi ve teşviklerin hacimleri değil aynı zamanda bu kredi ve teşviklerin derinliği ve ulaşılabilirliği de arttırılmalıdır.

Sanayileşme ve kentleşme karbon emisyonunu arttırmaktadır. Sanayileşmenin çevresel olumsuz etkilerini azaltmak için enerji verimliliğini ve çevresel standartları iyileştirecek reformist politikalar izlenmelidir. Ayrıca kentleşme süreçlerinde de şehirlerin altyapısal bağlamda daha verimli ve planlı bir şekilde oluşturulması sağlanmalıdır. Ek olarak özel 
taşıtlar yerine toplu taşıma kullanımı teşvik edilmeli, bunun için kapsamlı toplu taşıma ağları oluşturulmalıdır.

Son olarak Türkiye'de ÇKE hipotezinin geçerli olmadığı ve enerji tüketiminin karbon emisyonunu arttırdığ 1 tespit edilmiştir. ÇKE hipotezinin geçerli olmaması, gelir seviyesinin henüz çevresel bilinç yaratacak düzeylere ulaşmadığını göstermektedir. Bu çevresel bilinç, çevresel sürdürülebilirlik konusundaki eğitimlerin ve sosyal sermayenin arttırılması yoluyla oluşturulabilir. Ek olarak Yildirim vd. (2020) tarafından yapılan çalışmada da sosyal sermayenin iyileştirilmesinin Türkiye'deki çevresel politikaların etkinliğini arttırdığı bulunmuştur. $\mathrm{Bu}$ yüzden eğitim programlarına çevresel bilinci toplumsal düzeyde oluşturacak ders ve kursların adapte edilmesi gereklidir. Enerji tüketiminin çevre üzerindeki olumsuz etkisi de alternatif enerji türlerinin (nükleer, yenilenebilir enerji vs.) toplam enerji tüketimindeki payları arttırılarak giderilebilir. Bu kapsamda gerekli teşvik politikaları uygulanmalıdır. Alternatif enerjinin payında yaşanacak olan artış, sanayileşmenin olumsuz çevresel etkisini de sınırlayabilir.

Gelecekte yapılacak olan çalışmalarda, sanayileşme ve kentleşme süreçlerinin Türkiye'deki bölgesel çevresel bozulmayı nasıl etkilediği incelenerek daha ayrıntılı (ve bölgesel) politikalar sunulabilir. Bunun yanında küreselleşmenin diğer boyutları (siyasal ve sosyal) da ele alınarak, bu boyutlar bağlamında küreselleşmenin çevresel etkileri araştırılabilir.

Hakem Değerlendirmesi: Dış bağımsız.

Çıkar Çatışması: Yazar çıkar çatışması bildirmemiştir.

Finansal Destek: Yazar bu çalışma için finansal destek almadığını beyan etmiştir.

Peer-review: Externally peer-reviewed.

Conflict of Interest: The author has no conflict of interest to declare.

Grant Support: The author declared that this study has received no financial support.

\section{Kaynakça/References}

Akçay, S., \& Karasoy, A. (2018). Doğrudan Yabancı Yatırımlar ve Karbondioksit Emisyonu İlişkisi: Türkiye Örneği (The Relationship Between Foreign Direct Investments and Carbon Dioxide Emissions: The Case of Turkey). Ankara Üniversitesi SBF Dergisi, 73(2), 501-526. https://doi.org/https://doi.org/10.1501/SBFder_0000002507

Birdsall, N., \& Wheeler, D. (1993). Trade Policy and Industrial Pollution in Latin America: Where Are the Pollution Havens? The Journal of Environment \& Development, 2(1), 137-149. https://doi. org/10.1177/107049659300200107

BP Statistical Review of World Energy. (2019). Data. https://www.bp.com/en/global/corporate/energy-economics/ statistical-review-of-world-energy.html

Brown, S. P. A., \& McDonough, I. K. (2016). Using the Environmental Kuznets Curve to evaluate energy policy: Some practical considerations. Energy Policy, 98, 453-458. https://doi.org/10.1016/j.enpol.2016.09.020 
CAT. (2020). Turkey | Climate Action Tracker. https://climateactiontracker.org/countries/turkey/

Cetin, M., \& Ecevit, E. (2017). The Impact of Financial Development on Carbon Emissions Under The Structural Breaks : Empirical Evidence from Turkish Economy. International Journal of Economics Perspectives, 11(1), 64-78.

Dar, J. A., \& Asif, M. (2018). Does financial development improve environmental quality in Turkey? An application of endogenous structural breaks based cointegration approach. Management of Environmental Quality: An International Journal, 29(2), 368-384. https://doi.org/10.1108/MEQ-02-2017-0021

Day, T., Gonzales, S., \& Röschel, L. (2016). İklim Hareketine Geçmenin Yan Faydalarl: Türkiye İklim Taahhüdünün Değerlendirmesi.

Destek, M. A., \& Ozsoy, F. N. (2015). Relationships between economic growth, energy consumption, globalization, urbanization and environmental degradation in Turkey. International Journal of Energy and Statistics, 03(04), 1550017. https://doi.org/10.1142/S2335680415500179

Difiglio, C., Güray, B. Ş., \& Merdan, E. (2020). Türkiye Enerji Görünümü 2020. https://iicec.sabanciuniv.edu/teo

Dreher, A. (2006). Does globalization affect growth? Evidence from a new index of globalization. Applied Economics, 38(10), 1091-1110. https://doi.org/10.1080/00036840500392078

Gokmenoglu, K. K., Taspinar, N., \& Rahman, M. M. (2020). Military expenditure, financial development and environmental degradation in Turkey: A comparison ofCO2 emissions and ecological footprint. International Journal of Finance \& Economics, February 2019, 1-12. https://doi.org/10.1002/ijfe.1831

Gokmenoglu, K., \& Taspinar, N. (2016). The relationship between CO2 emissions, energy consumption, economic growth and FDI: the case of Turkey. Journal of International Trade \& Economic Development, 25(5), 706723. https://doi.org/10.1080/09638199.2015.1119876

Gygli, S., Haelg, F., Potrafke, N., \& Sturm, J.-E. (2019). The KOF Globalisation Index - revisited. The Review of International Organizations, 14(3), 543-574. https://doi.org/10.1007/s11558-019-09344-2

Halicioglu, F. (2009). An econometric study of CO2 emissions, energy consumption, income and foreign trade in Turkey. Energy Policy, 37(3), 1156-1164. https://doi.org/10.1016/j.enpol.2008.11.012

IMF. (2020). Financial Development Index Database. https://data.imf.org/?sk=F8032E80-B36C-43B1-AC26493C5B1CD33B

Kaika, D., \& Zervas, E. (2013). The Environmental Kuznets Curve (EKC) theory-Part A: Concept, causes and the CO2 emissions case. Energy Policy, 62, 1392-1402. https://doi.org/10.1016/j.enpol.2013.07.131

Karasoy, A. (2019). Drivers of carbon emissions in Turkey: considering asymmetric impacts. Environmental Science and Pollution Research, 26(9), 9219-9231. https://doi.org/10.1007/s11356-019-04354-4

Karasoy, Alper, \& Akçay, S. (2019). Effects of renewable energy consumption and trade on environmental pollution: The Turkish case. Management of Environmental Quality: An International Journal, 30(2), 437-455. https://doi.org/10.1108/MEQ-04-2018-0081

Katircioglu, S., \& Celebi, A. (2018). Testing the role of external debt in environmental degradation: empirical evidence from Turkey. Environmental Science and Pollution Research, 25(9), 8843-8852. https://doi. org/10.1007/s11356-018-1194-0

Katircioğlu, S. T., \& Taşpinar, N. (2017). Testing the moderating role of financial development in an environmental Kuznets curve: Empirical evidence from Turkey. Renewable and Sustainable Energy Reviews, 68(February 2015), 572-586. https://doi.org/10.1016/j.rser.2016.09.127

Kılıçarslan, Z., \& Dumrul, Y. (2017). Foreign Direct Investments and CO2 Emissions Relationship: The Case of Turkey. Business and Economics Research Journal, 4(8), 647-660. https://doi.org/10.20409/berj.2017.73

Koçak, E., \& Şarkgüneşi, A. (2018). The impact of foreign direct investment on CO2 emissions in Turkey: new evidence from cointegration and bootstrap causality analysis. Environmental Science and Pollution Research, 25(1), 790-804. https://doi.org/10.1007/s11356-017-0468-2 
KOF Swiss Economic Institute. (2020). KOF Globalisation Index. https://www.kof.ethz.ch/en/forecasts-andindicators/indicators/kof-globalisation-index.html

Lee, J., \& Strazicich, M. C. (2003). Minimum Lagrange Multiplier Unit Root Test with Two Structural Breaks. The Review of Economics and Statistics, 85(4), 1082-1089. http://www.jstor.org/stable/3211829

Lee, J., \& Strazicich, M. C. (2013). Minimum LM Unit Root Test with one Structural Break. Economics Bulletin, 33(4), 2483-2492.

McNown, R., Sam, C. Y., \& Goh, S. K. (2018). Bootstrapping the autoregressive distributed lag test for cointegration. Applied Economics, 50(13), 1509-1521. https://doi.org/10.1080/00036846.2017.1366643

Mert, M., \& Caglar, A. E. (2020). Testing pollution haven and pollution halo hypotheses for Turkey: a new perspective. Environmental Science and Pollution Research. https://doi.org/10.1007/s11356-020-09469-7

Mishkin, F. S. (2009). Globalization and financial development. Journal of Development Economics, 89(2), 164 169. https://doi.org/10.1016/j.jdeveco.2007.11.004

Ozatac, N., Gokmenoglu, K. K., \& Taspinar, N. (2017). Testing the EKC hypothesis by considering trade openness, urbanization, and financial development: the case of Turkey. Environmental Science and Pollution Research, 24(20), 16690-16701. https://doi.org/10.1007/s11356-017-9317-6

Özdemir, B. K., \& Koç, K. (2020). Türkiye'de Karbon Emisyonları, Yenilenebilir Enerji Ve Ekonomik Büyüme. Ege Stratejik Araştırmalar Dergisi, 11(1), 66-86. https://doi.org/10.18354/esam.665191

Ozturk, I., \& Acaravci, A. (2013). The long-run and causal analysis of energy, growth, openness and financial development on carbon emissions in Turkey. Energy Economics, 36, 262-267. https://doi.org/10.1016/j. eneco.2012.08.025

Öztürk, S., \& Saygın, S. (2020). Türkiye’de 1974-2016 Döneminde Yapısal Kırılma Altında Kişi Başına Reel Gelir, Doğrudan Yabancı Yatırımlar, Ticari Açıklık ve Karbon Emisyonları Arasındaki İlişki. Sosyoekonomi, 28(44), 69-90. https://doi.org/10.17233/sosyoekonomi.2020.02.04

Öztürk, Z., \& Öz, D. (2016). The Relationship between Energy Consumption, Income, Foreign Direct Investment, and CO2 Emissions: The Case of Turkey. Çankir Karatekin University Journal of the Faculty of Economics \& Administrative Sciences, 6(2), 269-288.

Pata, U. K. (2018). The effect of urbanization and industrialization on carbon emissions in Turkey: evidence from ARDL bounds testing procedure. Environmental Science and Pollution Research, 25(8), 7740-7747. https:// doi.org/10.1007/s11356-017-1088-6

Pesaran, M. H., \& Shin, Y. (1995). An Autoregressive Distributed-Lag Modelling Approach to Cointegration Analysis. Içinde S. Strom (Ed.), Econometrics and Economic Theory in the 20th Century (ss. 371-413). Cambridge University Press. https://doi.org/10.1017/CCOL521633230.011

Pesaran, M. H., Shin, Y., \& Smith, R. J. (2001). Bounds testing approaches to the analysis of level relationships. Journal of Applied Econometrics, 16(3), 289-326. https://doi.org/10.1002/jae.616

Sadorsky, P. (2010). The impact of financial development on energy consumption in emerging economies. Energy Policy, 38(5), 2528-2535. https://doi.org/10.1016/j.enpol.2009.12.048

Saini, N., \& Sighania, M. (2019). Environmental impact of economic growth, emission and FDI: systematic review of reviews. Qualitative Research in Financial Markets, 11(1), 81-134. https://doi.org/10.1108/QRFM-092017-0087

Sam, C. Y., McNown, R., \& Goh, S. K. (2019). An augmented autoregressive distributed lag bounds test for cointegration. Economic Modelling, 80, 130-141. https://doi.org/10.1016/j.econmod.2018.11.001

Seker, F., Ertugrul, H. M., \& Cetin, M. (2015). The impact of foreign direct investment on environmental quality: A bounds testing and causality analysis for Turkey. Renewable and Sustainable Energy Reviews, 52, 347-356. https://doi.org/10.1016/j.rser.2015.07.118 
Shangquan, G. (2000). Economic Globalization: Trends, Risks and Risk Prevention Contents. Içinde Economic \& Social Affairs (ST/ESA/2000/CDP/1; CDP Background Papers). http://www.un.org/esa/policy/devplan/

Svirydzenka, K. (2016). Introducing a New Broad-based Index of Financial Development. IMF Working Paper, January, 1-43.

Tamazian, A., Chousa, J. P., \& Vadlamannati, K. C. (2009). Does higher economic and financial development lead to environmental degradation: Evidence from BRIC countries. Energy Policy, 37(1), 246-253. https://doi. org/10.1016/j.enpol.2008.08.025

The World Bank. (2020). Dünya Kalkınma Göstergeleri. https://data.worldbank.org/data-catalog/worlddevelopment-indicators

Yildirim, J., Alpaslan, B., \& Eker, E. E. (2020). The role of social capital in environmental protection efforts: evidence from Turkey. Journal of Applied Statistics, 1-17. https://doi.org/10.1080/02664763.2020.1843609

Yuxiang, K., \& Chen, Z. (2011). Financial development and environmental performance: Evidence from China. Environment and Development Economics, 16(1), 93-111. https://doi.org/10.1017/S1355770X10000422 